\title{
IDENTIFICATION AND DRAPABILITY OF HIGH PERFORMANCE THERMOPLASTIC UD COMPOSITES FOR AERONAUTICAL APPLICATION
}

\author{
Badadjida Wintiba $^{1 *}$, Péter Z. Berke ${ }^{1}$, Frederic Lani ${ }^{2}$ and Thierry J. Massart ${ }^{1 *}$ \\ ${ }^{1}$ Université libre de Bruxelles (ULB), Building, Architecture \& Town Planning (BATir) Dept. CP \\ 194/02, Avenue F.D. Roosevelt 50, 1050 Bruxelles, Belgium \\ ${ }^{2}$ Solvay S.A., 1120 Bruxelles, Belgium \\ *bwintiba@ulb.ac.be
}

The use of fiber reinforced thermoplastics in the aircraft industry has been growing for decades due to their good strength/weight ratio. Thermoplastic UD composites exhibit a complex material behavior that is in part linked to their manufacturing process, and this makes their experimental identification very intricate. This motivates the use of coupled experimental-numerical investigations to characterize them. In the present computational modeling based contribution, the generalized Maxwell viscoelastic material behavior is used for forming simulations of APC thermoplastic composites. The APC thermoplastic composite is first idientified and then its in-plane shear and out of plane bending bevior are validated befor the finite elements forming simulations. In order to match the experimentally observed behavior of the material during forming operation, the membrane and bending stiffness are uncoupled in the forming simulations, as proposed in [1]. This uncoupling is performed through the use of dedicated superimposed shell and membrane finite elements combined with user subroutines in Abaqus, as illustrated in Figure 1. The results of full forming simulations of UD composites are compared qualitatively and quantitatively to experimental/numerical data available in the literature.

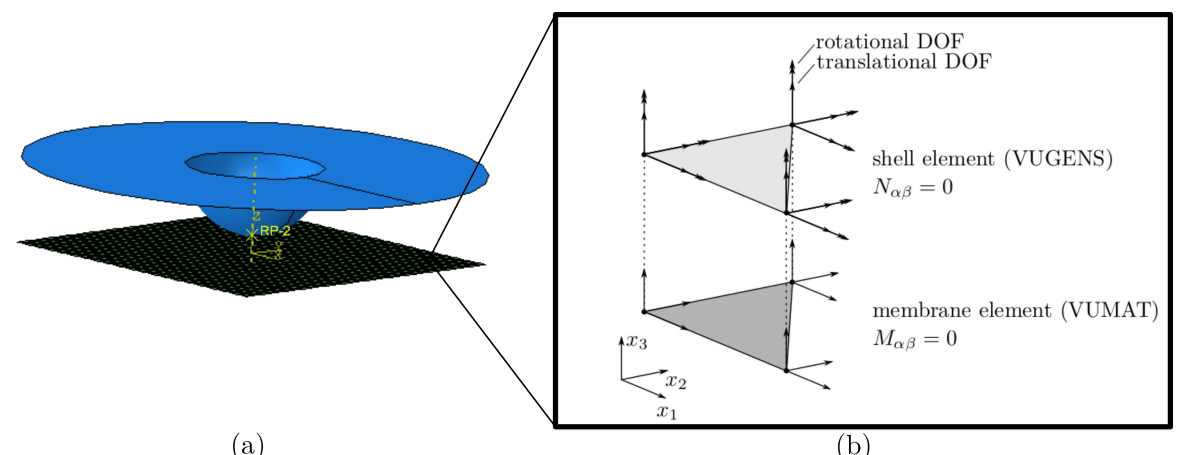

Figure 1: (a) Forming model, the thermoplastic UD composite is shown below, the stamp is shown in blue. (b) Superimposed shell and membrane finite elements employed to model the composite.

\section{References}

[1] D. Dörr and F. J. Schirmaier and F. Henning and L. Kärger (2017) A viscoelastic approach for modeling bending behavior in finite element forming simulation of continuously fiber reinforced composites. Composites Part A: Applied Science and Manufacturing, 94, pp.113-123. 